Article

\title{
An Improvement of Gain-Loss Price Bounds on Options Based on Binomial Tree and Market-Implied Risk-Neutral Distribution
}

\author{
Shi-jie Jiang ${ }^{1, *}$, Mujun Lei ${ }^{1}$ and Cheng-Huang Chung ${ }^{2}$ \\ 1 College of Finance and Statistics, Hunan University, No.109, Shijiachong Road, Changsha 410-006, China; \\ mujunlei@hnu.edu.cn \\ 2 Risk Management Department, Waterland Securities Co., Ltd., 5F., No.188, Sec. 5, Nanjing E. Rd., Songshan \\ Dist., Taipei City 10571, Taiwan; d92723013@ntu.edu.tw \\ * Correspondence: actjiang@msn.com
}

Received: 24 March 2018; Accepted: 5 June 2018; Published: 10 June 2018

\begin{abstract}
This paper investigates the approximated arbitrage bounds of option prices in an incomplete market setting and draws implications for option pricing and risk management. It gives consideration to periods of global financial crisis and European sovereign debt crisis. To this end, we employ the gain-loss ratio method combined with the market-implied risk-neutral distribution calculated by binomial tree to investigate the options price bounds. Our implied gain-loss bounds of option prices are preference-free and parametric-free to avoid the misspecification error of subjective choice on the benchmark model of gain-loss ratio, and consequently, greatly reduce model risk and market risk. The empirical results show that there are option prices breaking the gain-loss bounds, even after taking into account the market information. This means that a good risk management technique and good-deal investment opportunities exist if the implied binomial tree is used as a benchmark model in the gain-loss bounds.
\end{abstract}

Keywords: S\&P 500 index options; gain-loss ratio; risk-neutral distribution; binomial tree; risk management

\section{Introduction}

Asset pricing is an essential issue in financial economics. There are two main fundamental ideas that are explored in asset pricing: "equilibrium valuation" and "arbitrage-free valuation". If markets are complete, we can directly derive the equilibrium state prices by solving the individual agent's optimization problem, which maximizes the individual's utility function subjected to the wealth constraints. Following the equilibrium arguments, the Black-Scholes options pricing formula can be derived in a discrete-time economy [1,2], and the literature calls this an equilibrium valuation or a model-based pricing model. On the other hand, the arbitrage-free valuation, known as no-arbitrage pricing, says that a securities market price is arbitrage-free if there are no arbitrage opportunities [3]. A bundle of basis assets with given prices and an absence of arbitrage opportunity restricts the admissible set of pricing kernels. If the markets are complete, there is only one strictly positive vector of pricing kernel that correctly prices the basis assets. However, if the number of basis assets is fewer than the states of nature, the admissible set contains many pricing kernels that yield a range of asset prices [4]. For market participants, the main problem is that the prices obtained from the Black-Scholes model differ significantly from observed prices which have serious consequences for market participants measuring the market risk [5].

Two classical models, the good-deal bound model [6] and the gain-loss ratio model [7], propose a framework to unify the model-based model and no-arbitrage pricing model and tighten the pricing 
bounds by introducing additional restrictions. The good-deal bounds model [6] is developed by imposing a restriction on Sharpe ratio of pricing kernel's variance and strengthened the option price "semi-arbitrage" bounds. The gain-loss ratio model [7] imposes a restriction on the pricing kernel with respect to the gain-loss ratio on the expected gains to expected losses to limit the possibility of the pricing kernel deviating from a reference benchmark pricing model. This method also has a more stable result in pricing the deep out-of-money options comparing to good-deal bound [7]. When restricting the variance of pricing kernel smaller than the level of Sharpe ratio, the good-deal bound model [6] is equal to the gain-loss ratio model [7]. In order to achieve robustness, the gain-loss ratio model is utilized in this paper. However, one limitation of the gain-loss ratio model is that the model builder has to subjectively choice the reference pricing kernel or benchmarked model to construct the gain-loss bounds. This exposes the price bounds to various types of model risk.

Many researchers use option prices to infer a state price vector for further applications in financial studies [8,9]. Breeden and Litzenberger [10] derived the prices of elementary contingent claims from options, and they call this an "inverse problem", which is the process of calculating from a set of observations to get the causal factors that produced them. By means of a state price vector, we can construct the risk-neutral probability to obtain the asset price as its expected present value which greatly eases systematic valuation errors and market risk. Several methods have been developed to extract the risk-neutral probability distribution form option prices [11-14]. In the literature, the inverse problem can be classified into two categories. One is a parametric method that uses a set of parameters for prior risk-neutral probability distribution and calculates option prices by varying the parameters to minimize the pricing error, such as expansion methods [15], generalized distribution methods [16-18], and mixture methods $[19,20]$. The other category is nonparametric methods, which search the risk-neutral probability distribution without a prior assumption of a specific distribution, such as maximum entropy methods [21,22], kernel methods [23] and curve-fitting methods [24-27]. The implied binomial tree of Rubinstein [11], hereinafter referred to as "IBT model", is a classical model of the nonparametric approach. As one of the basket options, the pricing and hedging of S\&P 500 index option widely uses implied binomial trees $[28,29]$. Therefore, we follow this method.

In this article, we employ the IBT model to back out the risk-neutral probability and use the probability to replace the log-normal assumption (i.e., the normal distribution assumption for rate of returns) of the gain-loss bound. In other words, we use the market-implied distribution to calculate the option benchmark price and build up the gain-loss bounds, instead of using Black-Scholes log-normal assumption, which avoids the pricing errors resulting from the unrealistic assumption and gives a new idea of measuring market risk. To the best of our knowledge, it is the first attempt to employ the gain-loss ratio method combined with the market-implied risk neutral distribution which is calculated by a binomial tree setting. Using the S\&P 500 index option for the period from January 2008 to December 2014, we estimate or update the market-implied distribution every $30 \mathrm{~min}$ to refresh the price bounds and review the trading opportunities. Specifically, the sampling period gives consideration to periods of global financial crisis and European sovereign debt crisis. Our empirical results show that there are option prices breaking the gain-loss bounds, even after taking into account the market information, which means that a good risk management technique and good-deal investment opportunities exist if the implied binomial tree is used as a benchmark model in the gain-loss bounds.

It is noteworthy that there are several particular features in our market-implied risk-neutral distribution. First, we avoid a subjective assumption on the underlying distribution in building up the gain-loss bounds. Second, with the modification of the benchmark model, the model risk of our gain-loss ratio bounds can be greatly reduced. Third, we have a better exploitation of the deep-out-of-money option prices by market-implied option prices that are not explained well in previous models [6,7]. Fourth, by employing the gain-loss ratio method combined with the market-implied risk neutral distribution calculated by binomial tree, we reduce the risk of distributional misspecification. According to Rubinstein's study [11], there are many violations of Black-Scholes 
assumptions which are serious, difficult to remedy, and may destroy the arbitrage foundations of the Black-Scholes model. Our method provides an effective way to capture well the tail effects of the underlying asset distribution for both sides, which can provide market participants with a better model for option pricing and risk management.

The remainder of this paper is organized as follows: Section 2 presents the model based on a risk-neutral pricing kernel and sets the IBT method that can be employed to derive market-implied probability from the option data. Section 3 describes the selected S\&P 500 index option data and shows the estimated market-implied gain-loss option price bounds. Section 4 offers several conclusive considerations and implications.

\section{Methodology: Gain-Loss Pricing Bounds}

\subsection{The Properties of Gain-Loss Ratio}

Gain-loss ratio is a very appealing, interesting model with many advantages [30]. We briefly review the result of the gain-loss ratio and its application for the valuation of uncertain payoffs that were developed by Bernardo and Ledoit [7]. Let $\widetilde{z}=\left[\widetilde{z}_{1}, \ldots, \widetilde{z}_{s}\right] \in Z$ be the random payoffs and $\widetilde{x}=\widetilde{z}-\left(1+r_{f}\right) \pi(\widetilde{z})$ be the excess payoffs where $\pi(\widetilde{z})$ is payoff function. We define $\widetilde{x}^{+}=\max (\widetilde{x}, 0)$ as the positive part and $\widetilde{x}^{-}=\max (-\widetilde{x}, 0)$ as the negative part. $\widetilde{b}$ is the basis assets portfolio which payoff comes close to $\widetilde{z}$ from below and above, and $B$ represents the space for basis assets. We define two subsets for $B, A_{1}$ and $A_{2}$, which can be expressed as

$$
A_{1}=\left\{\widetilde{b}: \frac{E^{*}\left[(\widetilde{z}-\widetilde{b})^{+}\right]}{E^{*}\left[(\widetilde{z}-\widetilde{b})^{-}\right]} \geq \bar{L}\right\}, A_{2}=\left\{\widetilde{b}: \frac{E^{*}\left[(\widetilde{b}-\widetilde{z})^{+}\right]}{E^{*}\left[(\widetilde{b}-\widetilde{z})^{-}\right]} \geq \bar{L}\right\},
$$

where $E^{*}[\bullet]$ denotes the expectation value under the risk-adjusted probability measure. $E^{*}\left[\widetilde{x}^{+}\right] / E^{*}\left[\widetilde{x}^{-}\right]$ is the gain-loss ratio, hereinafter referred to as $\bar{L}$. And the gain-loss price bounds of a contingent claim are $\forall \widetilde{z} \in Z$ subject to $\widetilde{z} \notin B$

$$
\max _{\widetilde{b} \in B \cap A_{1}} \pi_{B}(\widetilde{b}) \leq \pi(\widetilde{z}) \leq \min _{\widetilde{b} \in B \cap A_{2}} \pi_{B}(\widetilde{b}) .
$$

As $\bar{L}$ increases, the bounds become wider; when $\bar{L}$ decreases, the bounds become narrower. In the limit, as $\bar{L}$ increases to infinity, the bounds converge to the no-arbitrage bounds; as $\bar{L}$ goes to unit, the bounds converge to the benchmark model price.

\subsection{The Implied Risk-Neutral Probability and IBT Model}

Rubenstein's IBT method [11] is introduced as follows. Firstly, assuming $S_{j}$ for $j=0, \ldots, n$ are the underlying asset prices at the end of the tree from lowest to highest. We denote the terminal ending nodal risk-neutral probabilities as $P^{\prime}{ }_{j}$ and $\Sigma_{j} P^{\prime}{ }_{j}=1 . P^{\prime}{ }_{j}$ can be inferred from the riskless interest rate, concurrent market prices of the underlying asset and its associated otherwise identical European options with different striking prices. Assuming the risk-neutral probability of one up-move over each period is $p^{\prime}$, then $P^{\prime}{ }_{j}=n ! p^{\prime j}\left(1-p^{\prime}\right)^{n-j} / j !(n-j)$ ! can be obtained from the binomial distribution. As $n$ increases, this probability distribution will approximately be log-normal. Let $\gamma$ and $\delta$ be the riskless interest return and the underlying asset payout return over each period, respectively. Finally, assuming $S^{b}$ to be the current bid price of the underlying asset adjusted with dividend payouts and $S^{a}$ to be the current ask price of the underlying asset adjusted with dividend payouts. $C_{i}^{b}$ for $i=1, \ldots, m$ is the bid price at the end of the tree and $C_{i}^{a}$ for $i=1, \ldots, m$ is the ask price at the end of the tree. The implied posterior risk-neutral probabilities, $P_{j}$, can be obtained from the following quadratic minimizing problem: 


$$
\begin{aligned}
& \min _{P_{j}} \sum_{j}\left(P_{j}-P^{\prime}{ }_{j}\right)^{2} \text { subject to } \\
& \sum_{j} P_{j}=1 \text { and } P_{j} \geq 0 \text { for } j=0, \ldots, n \\
& S^{b} \leq S \leq S^{a} \text { where } S=\sum_{j} P_{j} S_{j} / r^{n} \\
& C_{i}^{b} \leq C_{i} \leq C_{i}^{a} \text { where } C_{i}=\sum_{j} P_{j} \max \left[0, S_{j}-K_{i}\right] / r^{n} \text { for } i=1, \ldots, m
\end{aligned}
$$

where $K_{i}$ is the strike price for the option traded in the market. The sum of posterior risk-neutral probabilities $P_{j}$ is 1 and comes closest to a prior log-normal guessing. $P_{j}$ makes the present values of all observed options fall between the bid and ask prices. Although we adopted a specific minimization function and a specific prior, the optimization method is quite flexible. As long as a solution exists and the number of probabilities $n$ is greater than the number of options $m$, the solution will depend on the prior and minimization function chosen. The least squares form of the minimization function is just one of a number of candidates [11] (For instance, the Hellinger Distance is also a good candidate. The Hellinger Distance is defined in terms of the Hellinger integral, which is used to quantify the similarity between two probability distributions. In practice, the quadratic programming is much easier to perform than minimizing Hellinger Distance). Since our purpose is to employ the implied binomial trees model into the framework of gain-loss price bounds, we will remain on our focus. Besides, it is well known that none of the asset-pricing models can perfectly fit the real fluctuation of options, even the IBT model. A lot of factors cannot be adopted by the model, such as significant transactions costs or restrictions on short selling. However, in comparison to the BS model, IBT model has huge improvements in parameter risk control and market simulating, and it is the optimal benchmark model when you try to fit a basket option [28,29].

\subsection{Our Methodology: Implied Gain-Loss Option Pricing Bounds}

In the numerical example of Bernardo and Ledoit [7], the authors used the Black-Scholes risk-adjusted probability as the risk-neutral probability. Our model replaces the benchmark pricing kernel by an objective market-implied density abstracting from option transaction data. Here, we apply IBT's implied risk-neutral distribution. We define two subsets for $B, B_{1}$ and $B_{2}$, which can be expressed as

$$
B_{1}=\left[b_{i}: \frac{\sum_{i=1}^{I} P_{i}\left(b_{i}-C_{i}\right)^{+}}{\sum_{i=1}^{I} P_{i}\left(b_{i}-C_{i}\right)^{-}} \geq L\right], B_{2}=\left[b_{i}: \frac{\sum_{i=1}^{I} P_{i}\left(C_{i}-b_{i}\right)^{+}}{\sum_{i=1}^{I} P_{i}\left(C_{i}-b_{i}\right)^{-}} \geq L\right],
$$

where $b_{i}$ is the payoff in the $i$ th simulation of the replicating portfolio of basis assets with weight $w_{0}$ on the risk-free bond and weight $w_{1}$ on the option on the traded asset. And the IBT gain-loss price bounds of a contingent claim are

$$
\begin{array}{ccc}
\max _{\substack{w_{0}, w_{1} \in R \\
b_{i}=w_{0}+w_{1} S_{i}}} w_{0} e^{-r t}+w_{1} S \leq C \leq & \min _{w_{0}, w_{1} \in R} \\
b_{i} \in B_{1} & b_{0} e^{-r t}+w_{1} S . w_{1} S_{i} \\
b_{i} \in B_{2}
\end{array}
$$

And the benchmark call options price can be calculated as

$$
C=\sum_{i=1}^{I} P_{i}\left(S_{i}-K\right)^{+} e^{-r t} .
$$

As we can see, the study of Bernardo and Ledoit [7] proposed their price bounds under the Black-Scholes risk-adjusted probabilities, which involves many restricted assumptions that have been violated in the real world. Since the implied binomial trees model can provide a computationally effective way to value options even in the presence of various violations of assumptions [11], our modification incorporates more information which can greatly reduce the model risk of gain-loss pricing bounds. The advantages of this modification are (a) the implied gain-loss pricing bounds are 
parameter-free that directly conform to market data and avoid an incorrect model specification and (b) the market price of options incorporates the investor's preference and sentiments on the current market. By applying a market-implied pricing kernel, we can capture the investor's risk-taking attitude more sensitively than the pricing kernel of model-based approaches, and the extreme case is more likely to occur in the market-implied distribution which greatly reduces the market risk.

It is noticeable that, even after using the market-implied distribution, there still exits a pricing gap between the benchmark prices and market prices. First, in the above programming program, the IBT method tries to obtain an "average probability" over all strike prices at one time. This means that, in Equation (3), $P_{j}$ is an "average result" over various strike price $K_{i}$. The risk-neutral probability $P_{j}$ has to coordinate the pricing errors of all the market prices with various strike prices. Therefore, when we use one market-implied probability to calculate option prices, there exists estimate errors or pricing biases across options with different strike prices. (This issue is similar to using a flat volatility curve to price all options, instead of using a volatility smile curve). In other words, we may have various risk-neutral probabilities, $P_{j}$, for options with different strike prices. Here we use one risk-neutral probability, $P_{j}$ so that there exists some pricing gaps between real transaction prices and benchmark prices. Second, our model indeed suffers a small downside risk. Based on our model and the reality, the downside risk comes from the severe deviations from the mean-variance framework, which may result from market imperfections such as significant transactions costs, restrictions, and margins on short selling, taxes, non-competitive pricing, and other non-controllable events. Third, owing to the computational time, it is impossible to continuously calculate the market-implied density in practice. We therefore estimate the market-implied density every $30 \mathrm{~min}$. There are two reasons that we update our market-implied distributions every $30 \mathrm{~min}$. First, price fluctuations are quite normal in index option markets. If we update the distribution too frequently, it may incorporate too much redundant information. Second, nowadays, as we can gather the information from a more distant place than ever, the market prices of the index option may have different patterns even in a single day [31], and that is why Rubinstein [11] updated his model three times a day in his paper. To conduct analyses of S\&P 500 index options markets, some researchers updated average volume every $30 \mathrm{~min}$ [32], some researchers reported autocorrelations for changes in the mean and the standard deviation of risk neutral density measured over different time intervals, from $1 \mathrm{~min}$ to $30 \mathrm{~min}$ [33], and some researchers studied the relationship between information and price change by applying the $30 \mathrm{~min}$ interval [34]. Considering the tradeoff between robustness and effectiveness, the update frequency has to be set as neither too short nor too long. Following the previous literature, we chose $30 \mathrm{~min}$ as our model update frequency. Distinguishing volatility estimating, our method uses past or lag market data to estimate the whole distribution instead of estimating only one parameter. Therefore, we have a priori estimate on the distribution, and we then process the out-of-sample test every $30 \mathrm{~min}$. The details are described in Section 3.

\section{Data and Estimated Risk-Neutral Distribution}

This section describes how the implied risk-neutral probabilities are obtained from the market trading data. The market trading data of the S\&P 500 index options for both the call and put options listed in the Chicago Board Options Exchange are collected from 2 January 2008 to 30 December 2014. Most of previous literature concerning gain-loss ratio used simulated data [35,36]. Few researchers adopt the real trading data which are low frequency and single variety [37]. Comparing to these studies, our data are quite rich and varied by using as many as a hundred simultaneously traded options on the S\&P 500 index, all differing in strike price and time to expiration. We employ the MATLAB optimization procedure to perform the programming problem in Equation (3). We calculate the risk-neutral probabilities $P_{j}$ of the S\&P 500 index options for 200, 400, and 800 steps. 


\subsection{Market-Implied Distributions}

The market-implied distributions are estimated every $30 \mathrm{~min}$ during the sample period. We plot two examples of the risk-neutral probabilities distribution of the S\&P 500 index options on 5 August 2011 (maturing in 17 March 2012) and 5 August 2008 (maturing in 21 March 2009) in Figures 1 and 2, respectively. The distributions estimated from call options are depicted on the left side, and the distributions estimated from put options are depicted in the right side. These implied probabilities are plotted using 200, 400, and 800-step binomial trees. As we can see, in Figure 1, the choice of step of binomial tree does not greatly affect the distribution shapes. However, there is a sharp distinction between the risk-neutral initial guess (normal distribution) and the market-implied risk-neutral probability distribution. The risk-neutral implied distribution is more skewed and leptokurtic. Besides, the left tail is non-smooth, which means the extreme case is more likely to occur in market-implied distribution. Nowadays, black swan events appear more than ever, such as Snowden case, fiscal cliff, government shut down and so on. So, the left tail of the distribution tends to be thicker. Rubinstein [11] also found the same phenomenon too. He argued that the risk-neutral implied posterior distribution is slightly bimodal and more highly skewed and kurtotic and the bimodality coming from the lower tail ("crash-o-phobia") is quite common during the post-crash period. Recently, the market risk has become a focus of market participants due to spectacular bankruptcies like the Baring's Bank or the investment bank Lehman Brothers. As a result, the risk-neutral implied distribution has less market risk than the normal distribution. Figure 2 plots similar results for the S\&P 500 options on 5 August 2008.

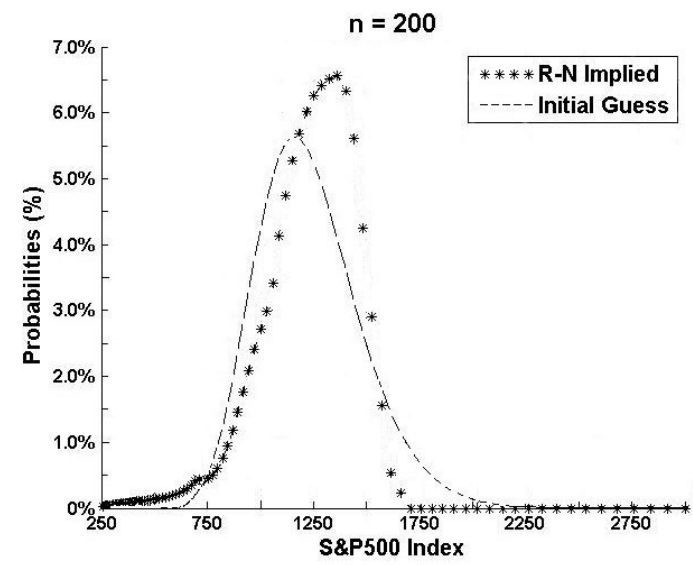

(a)

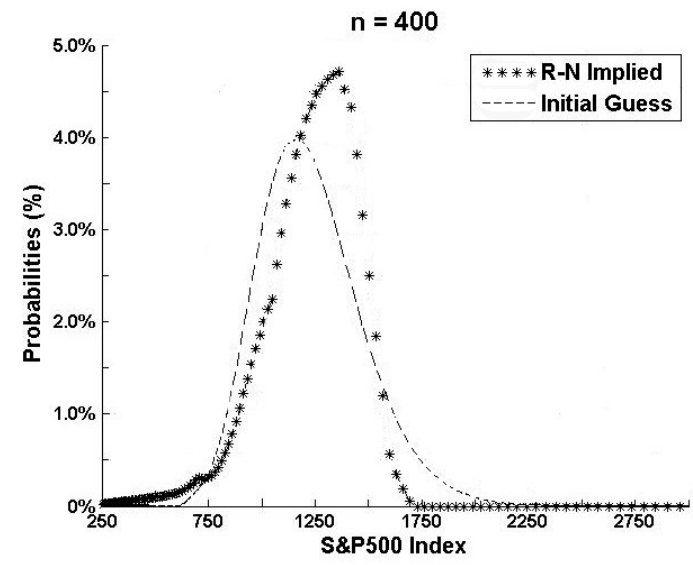

(c)

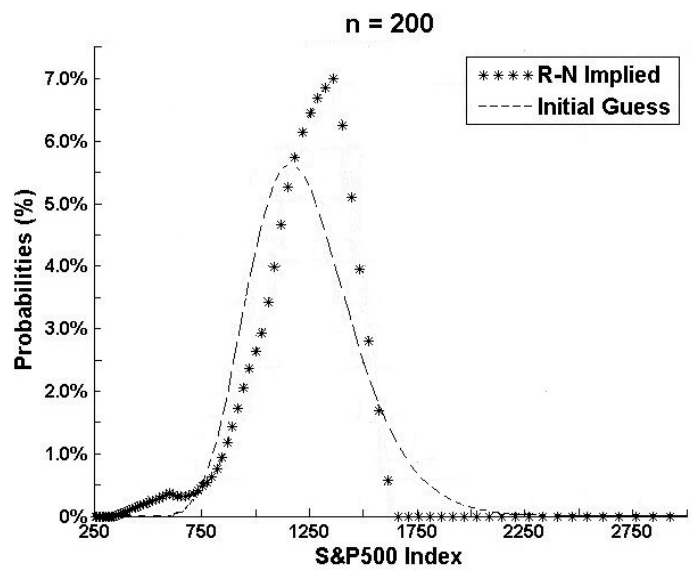

(b)

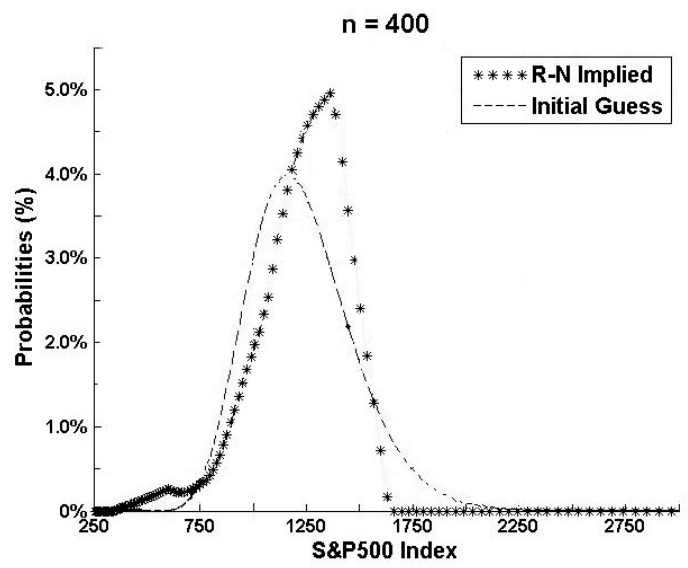

(d)

Figure 1. Cont. 


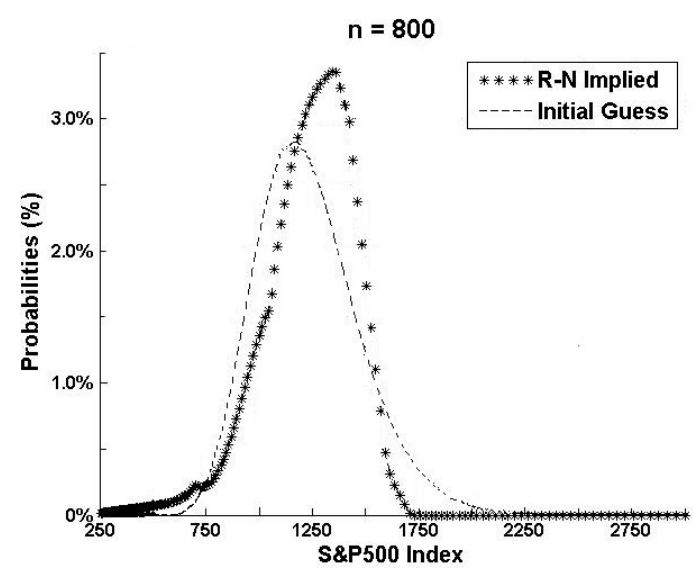

(e)

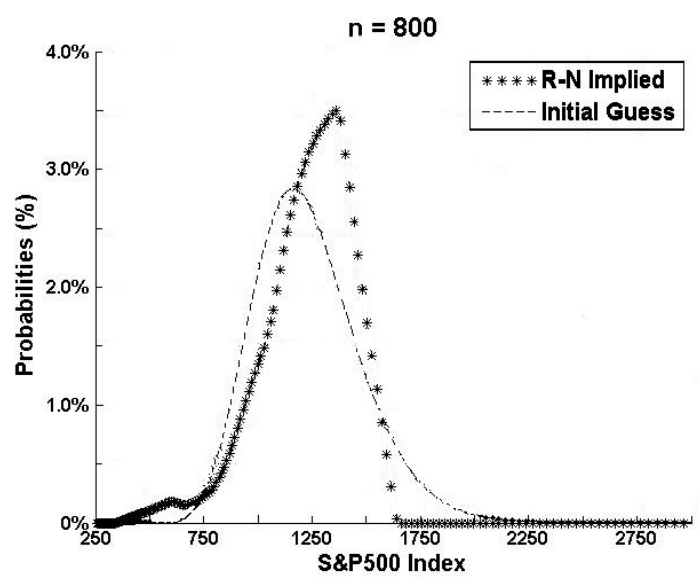

(f)

Figure 1. The risk-neutral probabilities of S\&P 500 index options on 5 August 2011. The three figures on the left side (a,c,e) are probability distributions for call options using 200,400, and 800-step binomial trees. The three figures on the right side $(\mathbf{b}, \mathbf{d}, \mathbf{f})$ are probability distributions for put options using 200, 400, and 800-step binomial trees.

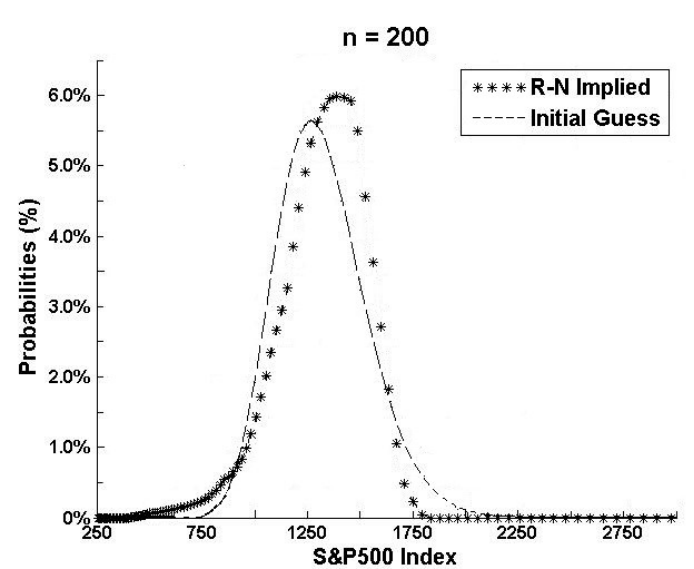

(a)

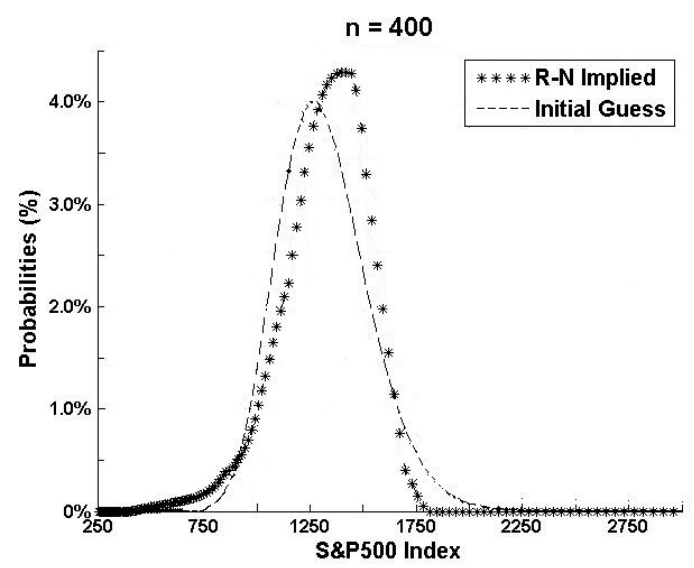

(c)

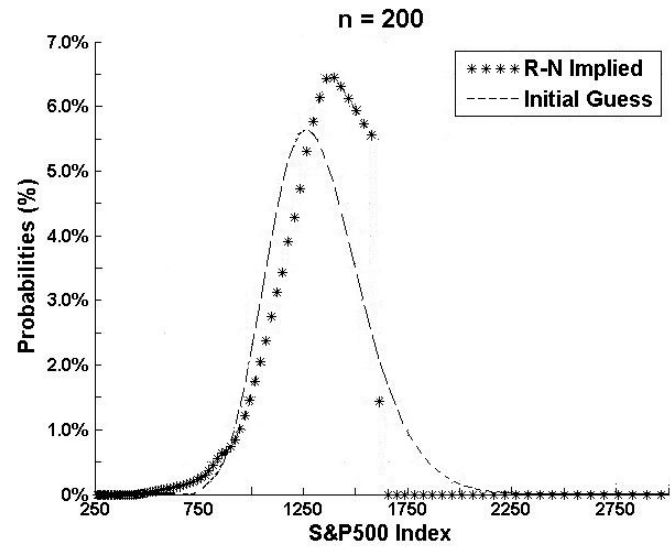

(b)

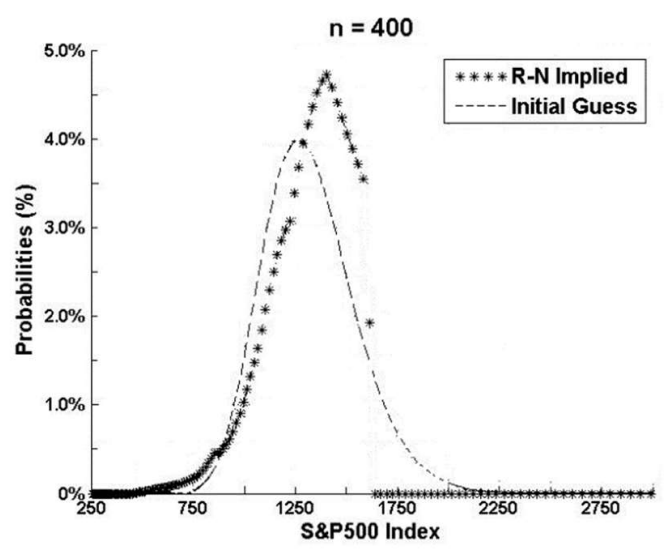

(d)

Figure 2. Cont. 


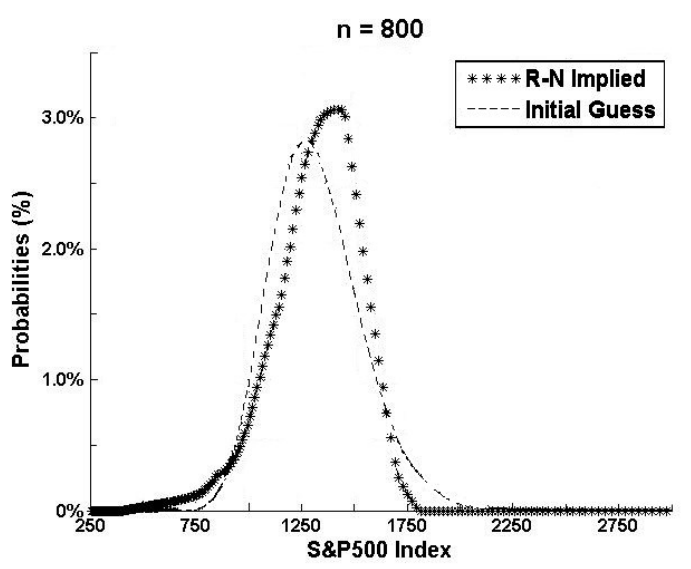

(e)

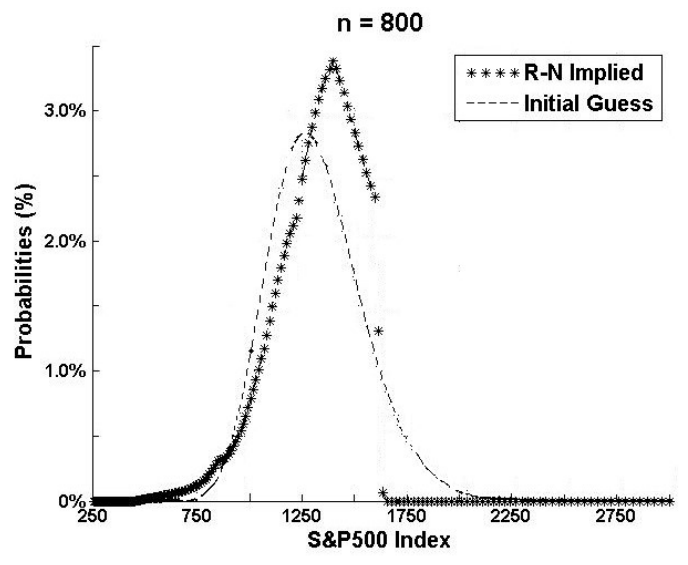

(f)

Figure 2. The risk-neutral probabilities of S\&P 500 index options on 5 August 2008. The three figures on the left side (a,c,e) are probability distributions for call options using 200,400, and 800-step binomial trees. The three figures on the right side $(\mathbf{b}, \mathbf{d}, \mathbf{f})$ are probability distributions for put options using 200 , 400 , and 800-step binomial trees.

\subsection{Market-Implied Option Pricing Bounds}

In Section 2, we propose the gain-loss price bounds. The option prices must lie between the bounds of Equation (5) to avoid a semi-arbitrage opportunity. This section shows how to find the option price bounds under given $\bar{L}$. Before calculating the gain-loss ratio bound, two subjective decisions have to be made. First is choosing a benchmark model to build up the theoretical prices. We employ both the Black-Scholes model (log-normal distribution) and the IBT model (market-implied distribution) to calculate benchmark prices. The other decision is to choose the value of gain-loss ratio, $\bar{L}$, to set up the gain-loss bounds under an incomplete market. We use $\bar{L}=3,5$, and 10 , respectively.

Figure 3 plots the gain-loss price bounds of call and put options using the Black-Scholes model as the benchmark model under $\bar{L}=1,2, \ldots, 10$ and $\bar{L}=200$, respectively. These options have a time to maturity of 225 days, a risk-free interest rate of $0.11 \%$, a strike price of $\$ 1100$, and a volatility of $25.38 \%$. The values of price bounds are reported in Appendix A Table A1. Different from Figure 3, Figure 4 plots the price bounds of call and put options using the IBT model as a benchmark model. The values of price bounds are reported in Appendix A Table A2.

As shown in both figures, the smaller the $\bar{L}$, the tighter the price bounds. As $\bar{L}$ is 1 , the upper bounds and lower bounds converge to the benchmark prices, and as $\bar{L}$ is 200 , they converge to the no-arbitrage bounds. There are two main fundamental ideas that are explored in asset pricing: model-based pricing and no-arbitrage pricing. Model-based pricing can derive the exact price of the option and no-arbitrage pricing can derive the range of option price. The gain-loss price bounds propose a framework to unify the model-based pricing and no-arbitrage pricing by introducing additional restrictions on gain-loss ratio. It means that if $\bar{L}$ goes to one (its lower bound), the admissible set shrinks to model-based pricing containing only the benchmark pricing kernel. If $\bar{L}$ goes to infinity, the admissible set grows to no-arbitrage pricing including all pricing kernels consistent with the absence of arbitrage among the basis assets. Besides, the price bounds get wider for the at-the-money option because the at-the-money options are the least redundant ones. As shown in Figure 4, we choose options having a time to maturity of 225 days, which makes the analyses incorporate more price fluctuations, like deep-out-of-money price. As we can see in Figures 3 and 4, comparing to initial Black-Scholes gain-loss price bounds, the IBT gain-loss price bounds are narrower for call options in deep-out-of-money and wider for put options in deep-out-of-money, which shows different price fluctuations in market-implied distributions and gives investors a total different market trading choice to avoid risks and get returns. Taking the price of the put option as an example, when the option 
prices are deep-out-of-money, investors will get a lower upper bound if they use Black-Scholes model as a benchmark model. Consequently, it makes them suffer a great risk generated from the rising prices of options due to the inaccurate estimate of the gain-loss price bounds. We also see that the price bounds in Figure 4 are wider than the bounds in Figure 3. The gain-loss price bounds using market-implied distribution are wider than the bounds of a log-normal distribution. This observation is consistent with our expectations. Because the market price of options reflects the traders' opinions and sentiments, it makes the implied distribution more sensitive than the Black-Scholes' log-normal assumption, which makes the implied distribution have less market risk. This phenomenon can also be explained by the shape differences between the market-implied distributions and the initial guess in Figures 1 and 2. The market-implied distribution is more skewed and leptokurtic than the normal distributions. Therefore, the extreme case is more likely to occur in market-implied distribution, and it results in wider gain-loss bounds.

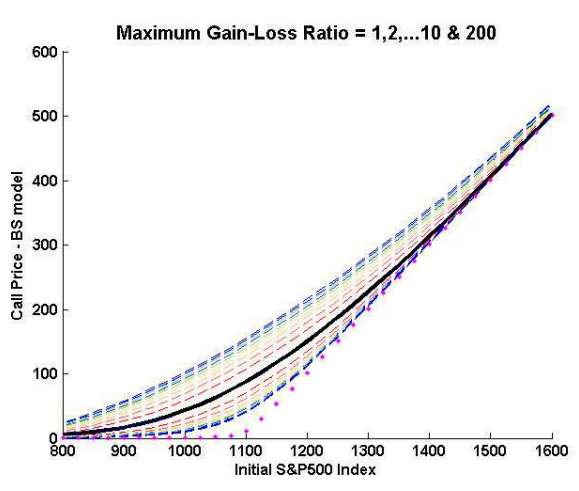

(a)

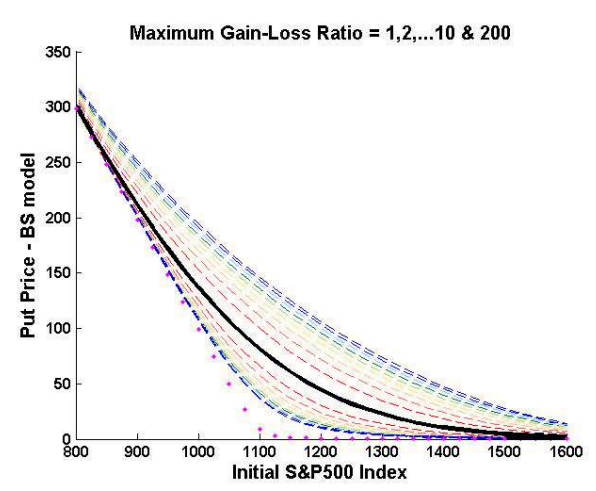

(b)

Figure 3. The gain-loss price bounds for both call options (a) and put options (b) by using Black-Scholes model as a benchmark model. The benchmark model is chosen to yield the Black-Scholes price given by the thick line in black. The thin lines in different colors represent the upper and lower bounds obtained by ruling out approximate arbitrage. For example, the red thin line represents the price bounds when gain-loss ratio equals to 2 . The orange thin line represents the price bounds when gain-loss ratio equals to 3 and so on, for other seven thin lines. The dotted line represents the bound obtained by ruling out pure arbitrage (gain-loss ratio equals to 200).

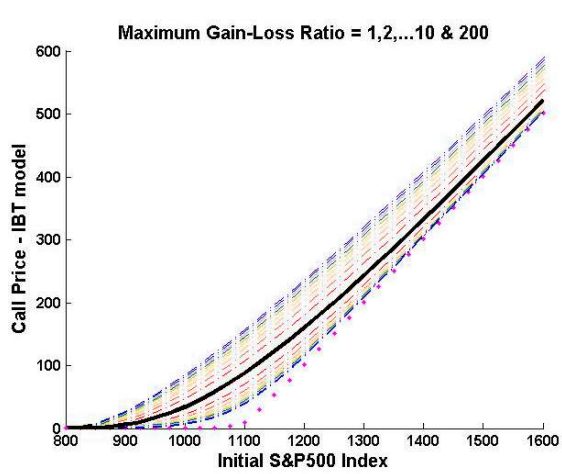

(a)

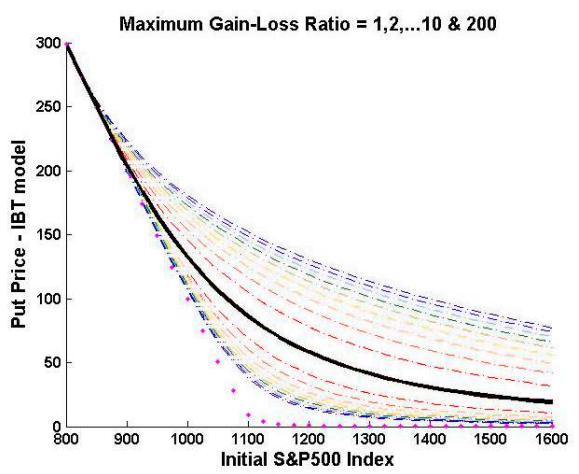

(b)

Figure 4. The gain-loss price bounds for both call options (a) and put options (b) by using IBT model as a benchmark model. The benchmark model is chosen to yield the IBT price given by the thick line in black. The thin lines in different colors represent the upper and lower bounds obtained by ruling out approximate arbitrage. For example, the red thin line represents the price bounds when gain-loss ratio equals to 2 . The orange thin line represents the price bounds when gain-loss ratio equals to 3 and so on, for other seven thin lines. The dotted line represents the bound obtained by ruling out pure arbitrage (gain-loss ratio equals to 200). 


\subsection{The Good Deal Trading Strategy}

Following the gain-loss bounds in Section 3.2, our trading strategies are selling the options whose prices are higher than the upper bounds and buying the options whose prices are smaller than the lower bounds with a complete buy and sell trade transaction cost of $1 \%$ [38]. The key parameter in the Black-Scholes formula, volatility, is updated every $30 \mathrm{~min}$ in each trading day. (We use three models to forecast daily volatility: GARCH, EGARCH, and GJR-GARCH. The choice of volatility model does not greatly affect the bounds and strategy performances, so we only show the results of GARCH. Other results can be provided upon request). The market-implied distribution is also updated or re-estimated at the same frequency. Given the market-implied distribution, the theoretical price of IBT model can be calculated by Equation (5), and $P_{j}$ and $S_{j}$ are obtained from the minimizing programming in Equation (3). The buying strategy is when the price smaller than the lower bound implied by $\bar{L}$ in Equation (5), we buy the option. The selling strategy is when the price is higher than the upper bound implied by $\bar{L}$ in Equation (5), we sell the option. The investment period is once the option purchased or sold, we hold the position to maturity day.

Table 1 shows the annual return of the selling strategy subjected to $\bar{L}=3,5$, and 10 . The benchmark price is calculated by the Black-Scholes model and the IBT model, respectively. In Table 1, the positive returns mean that the selling strategy achieves positive returns for both strategies from 2008 to 2014 . Bernardo and Ledoit [7] argued that the attractiveness of an investment opportunity is measured by the "gain-loss" ratio, which is the expectation of the investment's positive excess payoffs divided by the expectation of its negative excess payoffs. When applying our IBT price bounds to the real world, there is an important thing we need to consider: the trading opportunities. In theory, a bigger gain-loss ratio causes bigger rates of returns. But a bigger gain-loss ratio means the expectation of the investment's positive excess payoffs exceed the expectation of its negative excess payoffs far more, which appear rarely in the option markets. As a result, there is a tradeoff between the gain-loss ratio and trading opportunities. We therefore use cumulative returns to show the net returns during the whole investment period. The cumulative returns are shown in the last row in both Tables 1 and 2. Based on the empirical results, $=10$ has the highest cumulative returns in average. Thus, it is the best in reality. It means that the IBT model incorporates more market information than the Black-Scholes model which results in having less market risk and better investment performance. These findings support the statement that the IBT gain-loss price bounds are more useful than the Black-Scholes gain-loss price bounds in risk management and return performance. As mentioned above, implied binomial trees model can provide a computationally effective way to value options even in the presence of violations of Black-Scholes model's assumptions. Therefore, our IBT gain-loss price bounds will provide a better model for option pricing than initial gain-loss pricing bounds.

Table 1. Annual return of the selling strategy subjected to different $\bar{L}$ using Black-Scholes and IBT as benchmark models.

\begin{tabular}{ccccccc}
\hline & \multicolumn{2}{c}{ Annual Return under BS Bounds } & \multicolumn{2}{c}{ Annual Return under IBT Bounds } \\
\hline Year & $\bar{L}=3$ & $\bar{L}=5$ & $\bar{L}=10$ & $\bar{L}=3$ & $\bar{L}=5$ & $\bar{L}=10$ \\
2008 & $3.41 \%$ & $4.52 \%$ & $7.61 \%$ & $10.06 \%$ & $13.21 \%$ & $14.88 \%$ \\
2009 & $1.45 \%$ & $1.54 \%$ & $1.68 \%$ & $4.50 \%$ & $4.75 \%$ & $5.63 \%$ \\
2010 & $0.55 \%$ & $1.35 \%$ & $1.52 \%$ & $2.66 \%$ & $3.15 \%$ & $4.27 \%$ \\
2011 & $3.75 \%$ & $4.51 \%$ & $6.69 \%$ & $6.99 \%$ & $6.77 \%$ & $7.64 \%$ \\
2012 & $2.75 \%$ & $3.95 \%$ & $5.07 \%$ & $6.71 \%$ & $5.28 \%$ & $10.58 \%$ \\
2013 & $0.19 \%$ & $0.44 \%$ & $0.67 \%$ & $0.71 \%$ & $0.97 \%$ & $2.89 \%$ \\
2014 & $1.41 \%$ & $2.08 \%$ & $3.21 \%$ & $1.71 \%$ & $3.09 \%$ & $4.34 \%$ \\
Cumulative returns & $14.25 \%$ & $19.81 \%$ & $29.38 \%$ & $38.08 \%$ & $43.12 \%$ & $61.68 \%$ \\
\hline
\end{tabular}

Figure 5 shows the return distributions of all selling opportunities under $\bar{L}=3,5$, and 10 from 2008 to 2014. In Figure 5, as we increase the gain-loss ratio, $\bar{L}$, the distribution shifts to the right, 
the returns increase, and the frequency of extreme losses decreases. However, there still exists the result of some negative returns, which means that this strategy still suffers risk in extreme cases with very small probabilities.
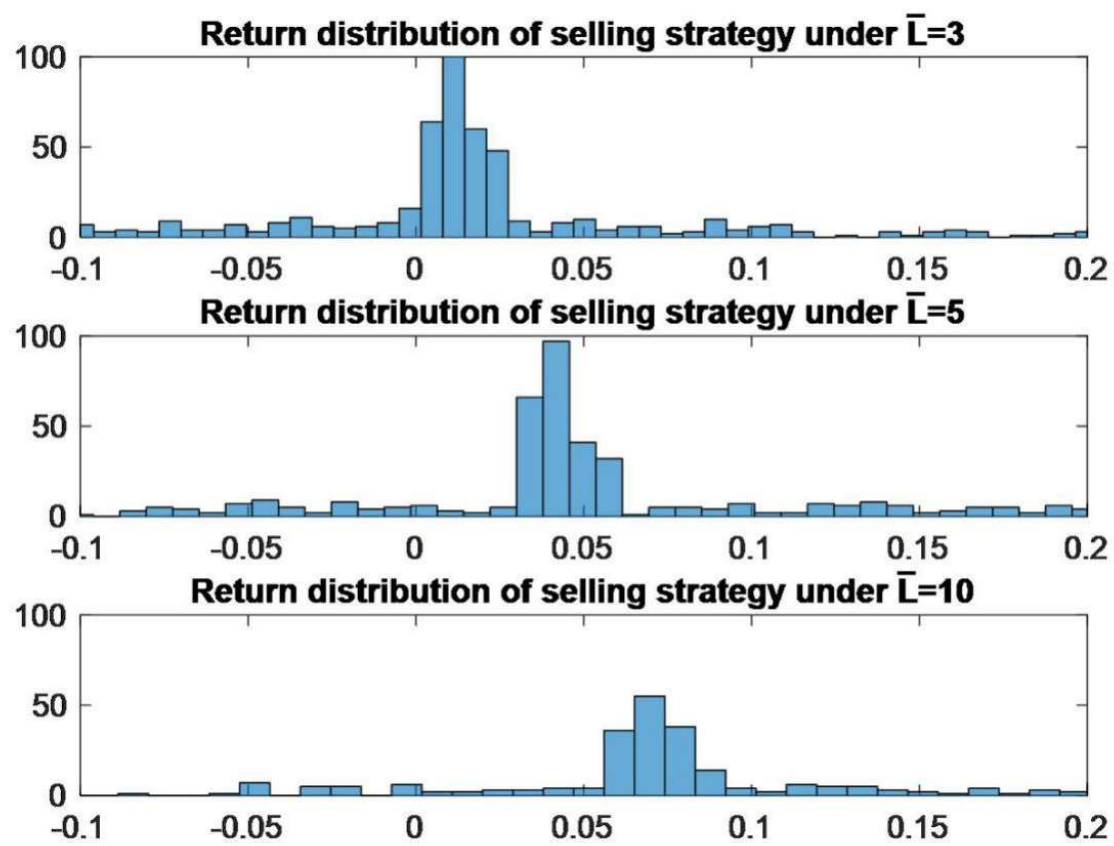

Figure 5. Return distribution of selling strategy under IBT gain-loss bounds.

Table 2 shows the annual returns of a buying strategy subjected to different $\bar{L}$. The benchmark prices are calculated by the Black-Scholes model and the IBT model, respectively. As shown in Table 2, there are many blanks in the annual return, which means no trading opportunities are available from 2008 to 2014. The trading opportunities only exist in the gain-loss bound with $\bar{L}=3$ and $\bar{L}=5$. No trading opportunity exists in $\bar{L}=10$ for both methods.

Table 2. Annual return of the buying strategy subjected to different $\bar{L}$ using Black-Scholes and IBT as benchmark models.

\begin{tabular}{ccccc}
\hline & \multicolumn{2}{c}{ Annual Return under BS Bounds } & \multicolumn{2}{c}{ Annual Return under IBT Bounds } \\
\hline Year & $\bar{L}=3$ & $\bar{L}=5$ & $\bar{L}=3$ & $\bar{L}=5$ \\
2008 & $91.19 \%$ & $51.86 \%$ & $182.42 \%$ & $196.10 \%$ \\
2009 & $-7.09 \%$ & - & $0.58 \%$ & - \\
2010 & $-59.88 \%$ & - & $-40.64 \%$ & - \\
2011 & $-44.23 \%$ & - & $-23.62 \%$ & - \\
2012 & $-73.01 \%$ & - & $-51.93 \%$ & - \\
2013 & $-62.72 \%$ & $-65.38 \%$ & $-55.48 \%$ & $-39.39 \%$ \\
2014 & $-0.85 \%$ & - & $-2.62 \%$ & - \\
Cumulative returns & $-96.03 \%$ & $-47.43 \%$ & $-73.16 \%$ & $79.47 \%$ \\
\hline
\end{tabular}

Note: - means no trading opportunity exists.

Figure 6 shows the daily returns of a buying strategy subjected to different gain-loss ratios from 2008 to 2014. In Figure 6, on increasing the gain-loss ratio, the distribution shifts to the right, and the returns increase. However, the trading opportunities decrease sharply. We can also observe that most of the returns are about $-100 \%$, which means that the investor loses all the option premiums in the buying strategy. In this vein, we cannot confirm that the buying strategy is a good-deal strategy as the selling strategy dose. 

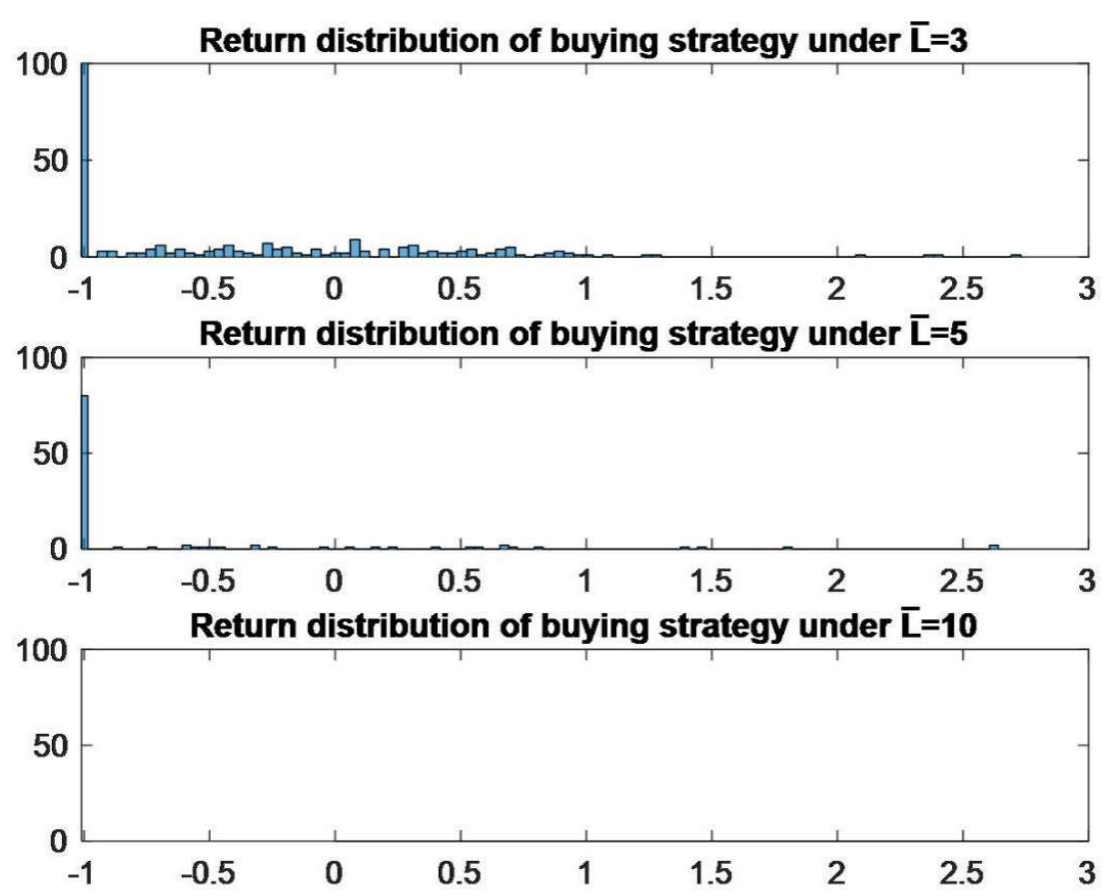

Figure 6. Return distribution of buying strategy under IBT gain-loss bounds.

In addition, there are some concerns when applying IBT price bounds in the real world. Firstly, the trading strategies in Table 1 are selling the options (put options or call options) whose prices are higher than the upper bounds and hold the position to the maturity. When applying our IBT price bounds to the real world, the trading opportunities need to be considered. For instance, if the gain-loss ratio is identical for various years, the year that the price fluctuates more frequently will have more trading opportunities, and thus, more returns. As a result, in the year 2008, the market was in more panic than ever, and the option prices fluctuated more than the following two years, which meant more trading opportunities and more returns. Besides, during the period of the Financial Crisis in the year 2008, due to the sheep-flock effect, the deviation of options prices from the benchmark prices became larger, which made the IBT gain-loss price bounds have more extra returns than the following two years. Secondly, the market prices of options reflect the traders' opinions and sentiments, and it makes the implied distribution more sensitive than the log-normal assumption of Black-Scholes model. Since IBT bounds are much wider than the BS bounds, some reasonably good option prices based on BS bounds may not be considered in that way in our IBT bounds. These somewhat good prices in BS bounds trigger a buying signal for the investors, consequently, causing them to lose money. For instance, due to more information has been considered in our model, it gives better buying signals than that of the BS bounds in the year 2009.

In sum, the selling strategy has a good performance on average return and the buying strategy has fewer trading opportunities but a poor performance on average return. After filtering by the gain-loss bounds of both strategies, the selling strategy provides a better annual return then the naïve buy-and-hold strategy. Finally, the gain-loss bounds of IBT method outperform the bounds of the Black-Scholes method in the sampling period.

\section{Conclusions}

In this paper, we compute the pricing bounds on the S\&P 500 index option based on a market-implied distribution and a gain-loss restriction. We use the IBT model to refine the market-implied distribution, which can have less market risk for proceeding in efficient risk management. The estimated risk-neutral pricing kernel implicitly reflects the investor's preference and sentiment, which can reconcile the latest information in the market and reduce the market risk. 
The empirical results show that when we increase the restriction on gain-loss ratio, the return of the strategies can approximately increase. We also confirm that the gain-loss bounds of the IBT method outperform the gain-loss bounds of the Black-Scholes model, which means the IBT model incorporates more market information than the Black-Scholes model; consequently, it results in having less market risk and better investment performance. Finally, the selling strategy has been evidenced to have a better performance than the buying strategy.

Several limitations to this study must be mentioned. First, the gain-loss bound we used might still suffer parameter and model risks. For example, the stochastic process in the stock index involves jumps that are not directly characterized in our model. We infer the jump probability by the option data and the implied risk-neutral probability, indirectly. However, the underlying assets in this study (i.e., S\&P 500) are less likely to experience jumps than any of their component equities, and most other underlying assets such as commodities, currencies, and bonds [11]; how to design an IBT model to handle jumps; or stochastic volatility would be an interesting agenda and could be left for future studies. Second, there exists a trade-off between the trading opportunity and rate of return. When we raise $\bar{L}$, the return increases; however, the trading opportunity decreases sharply. When we decrease $\bar{L}$, the return decreases; however, the trading opportunity increases. The optimal trade-off strategy between absolute return and trading frequency is not explored in this article. Third, as shown in Figure 5, a small downside risk in the selling strategy still suffers, which cannot be mitigated or eliminated by the IBT gain-loss bound. To sum up, the IBT model still suffers from misspecification error but is superior to the BS model, while the no-arbitrary pricing model is robust in asset pricing but is too imprecise to be economically interesting. In this paper, the IBT gain-loss price bounds can greatly reduce the weaknesses of IBT model and no-arbitrary pricing model.

On the suggestion for further works, we propose that the objective function in Equation (3) could be revised. For example, we can minimize the difference of an option's implied volatility of Black-Scholes model instead of minimizing the distance of the probability distributions. The implied volatility can avoid the disturbances of size effects of option prices resulting from different exercise prices and time to maturities. Finally, a subjective method to decide the ceiling value of $\bar{L}$ is also worthwhile for further research. The problem due to the arbitrary chosen ceiling value of $\bar{L}$ could be left for future studies.

Author Contributions: Shi-Jie Jiang and Mujun Lei conceived the empirical study, contributed analysis tools and finalized the paper; Cheng-Huang Chung designed and performed the simulation study and analyzed the data. All authors read and approved the final manuscript.

Acknowledgments: We are grateful to the editor, Professor Jeffery Tzuhao Tsai and three anonymous referees for their helpful comments and useful references which led to an improved version of this paper. Our work was supported by Ministry of Education, Humanities and Social Science Research Project (No. 17YJA790035).

Conflicts of Interest: The authors declare no conflict of interest.

\section{Appendix}

The appendix illustrates the detailed number of price bound plotted in Figures 3 and 4 . We only show the call option price bounds, and the tables of put option can be provided upon request. 
Table A1. Call Option Price Bounds on 5 August 2011 using Black-Scholes as benchmark model.

\begin{tabular}{|c|c|c|c|c|c|c|c|c|c|c|c|c|c|c|c|c|c|}
\hline \multirow[b]{2}{*}{$\bar{L}$} & \multicolumn{17}{|c|}{ Upper Bound } \\
\hline & 800 & 825 & 850 & 875 & 900 & 925 & 950 & 975 & 1000 & 1025 & 1050 & 1075 & 1100 & 1125 & 1150 & 1175 & 1200 \\
\hline 1 & 4.37 & 6.42 & 9.12 & 12.43 & 16.51 & 21.50 & 27.52 & 34.66 & 42.93 & 52.40 & 63.09 & 74.96 & 87.93 & 102.00 & 117.13 & 133.25 & 150.36 \\
\hline 2 & 7.92 & 11.25 & 15.46 & 20.47 & 26.29 & 33.04 & 40.75 & 49.46 & 59.14 & 69.80 & 81.41 & 93.93 & 107.28 & 121.46 & 136.43 & 152.16 & 168.65 \\
\hline 3 & 10.91 & 15.15 & 20.32 & 26.36 & 33.27 & 41.00 & 49.62 & 59.13 & 69.49 & 80.70 & 92.74 & 105.55 & 119.08 & 133.31 & 148.22 & 163.78 & 180.00 \\
\hline 8 & 21.38 & 28.06 & 35.59 & 43.89 & 52.95 & 62.75 & 73.25 & 84.41 & 96.18 & 108.54 & 121.45 & 134.90 & 148.84 & 163.26 & 178.15 & 193.50 & 209.31 \\
\hline 9 & 22.94 & 29.92 & 37.72 & 46.28 & 55.54 & 65.54 & 76.22 & 87.53 & 99.44 & 111.90 & 124.92 & 138.44 & 152.42 & 166.88 & 181.79 & 197.13 & 212.92 \\
\hline 10 & 24.39 & 31.62 & 39.68 & 48.45 & 57.92 & 68.08 & 78.90 & 90.35 & 102.36 & 114.93 & 128.02 & 141.60 & 155.64 & 170.12 & 185.05 & 200.39 & 216.17 \\
\hline 200 & 81.97 & 94.18 & 106.82 & 119.75 & 132.98 & 146.53 & 160.39 & 174.53 & 188.96 & 203.64 & 218.57 & 233.74 & 249.13 & 264.74 & 280.56 & 296.58 & 312.80 \\
\hline Inf & 800.00 & 825.00 & 850.00 & 875.00 & 900.00 & 925.00 & 950.00 & 975.00 & 1000.00 & 1025.00 & 1050.00 & 1075.00 & 1100.00 & 1125.00 & 1150.00 & 1175.00 & 1200.00 \\
\hline $\mathrm{s}$ & \multicolumn{17}{|c|}{$\mathrm{S}_{0}$} \\
\hline $\bar{L}$ & & 825 & 850 & 875 & 900 & 925 & 950 & 975 & 1000 & 1025 & 1050 & 1075 & 1100 & 1125 & 1150 & 1175 & 1200 \\
\hline 1 & 4.37 & 6.42 & 9.12 & 12.43 & 16.51 & 21.50 & 27.52 & 34.66 & 42.93 & 52.40 & 63.09 & 74.96 & 87.93 & 102.00 & 117.13 & 133.25 & 150.36 \\
\hline 2 & 2.32 & 3.49 & 5.07 & 7.08 & 9.70 & 13.07 & 17.39 & 22.84 & 29.52 & 37.61 & 47.21 & 58.36 & 70.99 & 85.11 & 100.66 & 117.49 & 135.58 \\
\hline 3 & 1.58 & 2.40 & 3.51 & 4.96 & 6.90 & 9.45 & 12.85 & 17.29 & 22.94 & 30.08 & 38.92 & 49.54 & 61.92 & 76.09 & 91.95 & 109.31 & 128.07 \\
\hline 8 & 0.61 & 0.94 & 1.39 & 1.99 & 2.84 & 4.00 & 5.67 & 8.02 & 11.30 & 16.01 & 22.62 & 31.62 & 43.29 & 57.77 & 74.81 & 93.87 & 114.54 \\
\hline 9 & 0.54 & 0.84 & 1.24 & 1.78 & 2.54 & 3.58 & 5.11 & 7.25 & 10.29 & 14.71 & 21.03 & 29.80 & 41.37 & 55.91 & 73.13 & 92.42 & 113.35 \\
\hline 10 & 0.49 & 0.75 & 1.12 & 1.61 & 2.30 & 3.25 & 4.64 & 6.62 & 9.45 & 13.62 & 19.68 & 28.23 & 39.71 & 54.31 & 71.70 & 91.20 & 112.35 \\
\hline 200 & 0.02 & 0.04 & 0.06 & 0.08 & 0.12 & 0.17 & 0.26 & 0.38 & 0.58 & 0.95 & 1.71 & 3.63 & 10.90 & 29.28 & 52.60 & 76.85 & 101.49 \\
\hline \multirow[t]{2}{*}{-Inf } & 0.00 & 0.00 & 0.00 & 0.00 & 0.00 & 0.00 & 0.00 & 0.00 & 0.00 & 0.00 & 0.00 & 0.00 & 0.75 & 25.75 & 50.75 & 75.75 & 100.75 \\
\hline & \multicolumn{16}{|c|}{ Upper Bound } & \\
\hline $\bar{L}$ & 1225 & 1250 & 1275 & 1300 & 1325 & 1350 & 1375 & 1400 & 1425 & 1450 & 1475 & 1500 & 1525 & 1550 & 1575 & 1600 & \\
\hline 1 & 168.37 & 187.22 & 206.80 & 227.06 & 247.90 & 269.26 & 291.15 & 313.49 & 336.25 & 359.35 & 382.77 & 406.45 & 430.34 & 454.40 & $\begin{array}{l}478.64 \\
\end{array}$ & 503.01 & \\
\hline 2 & 185.85 & 203.74 & 222.26 & 241.38 & 261.05 & 281.23 & 301.96 & 323.18 & 344.87 & 366.99 & 389.51 & 412.38 & 435.54 & 458.96 & 482.65 & 506.56 & \\
\hline 3 & 196.84 & 214.28 & 232.28 & 250.83 & 269.88 & 289.42 & 309.48 & 330.03 & 351.07 & 372.55 & 394.46 & 416.73 & 439.34 & 462.28 & 485.54 & 509.07 & \\
\hline 8 & 225.57 & 242.27 & 259.39 & 276.95 & 294.90 & 313.25 & 332.03 & 351.23 & 370.80 & 390.77 & 411.16 & 431.98 & 453.19 & 474.78 & 496.75 & 519.08 & \\
\hline 9 & 229.14 & 245.80 & 262.87 & 280.34 & 298.19 & 316.44 & 335.10 & 354.14 & 373.56 & 393.38 & 413.62 & 434.28 & 455.33 & 476.76 & 498.57 & 520.72 & \\
\hline 10 & 232.37 & 248.99 & 266.00 & 283.40 & 301.19 & 319.34 & 337.89 & 356.79 & 376.09 & 395.78 & 415.90 & 436.42 & 457.33 & 478.62 & 500.28 & 522.27 & \\
\hline 200 & 329.21 & 345.83 & 362.62 & 379.59 & 396.73 & 414.04 & 431.55 & 449.21 & 467.00 & 484.96 & 503.08 & 521.35 & 539.78 & 558.32 & 577.02 & 595.99 & \\
\hline \multirow[t]{2}{*}{ Inf } & 1225.00 & 1250.00 & 1275.00 & 1300.00 & 1325.00 & 1350.00 & 1375.00 & 1400.00 & 1425.00 & 1450.00 & 1475.00 & 1500.00 & 1525.00 & 1550.00 & 1575.00 & 1600.00 & \\
\hline & \multicolumn{17}{|c|}{ Lower Bound } \\
\hline $\bar{L}$ & 1225 & 1250 & 1275 & 1300 & 1325 & 1350 & 1375 & 1400 & 1425 & 1450 & 1475 & 1500 & 1525 & 1550 & 1575 & 1600 & \\
\hline 1 & 168.37 & 187.22 & 206.80 & 227.06 & 247.90 & 269.26 & 291.15 & 313.49 & 336.25 & 359.35 & 382.77 & 406.45 & 430.34 & 454.40 & 478.64 & 503.01 & \\
\hline 2 & 154.74 & 174.85 & 195.73 & 217.30 & 239.42 & 261.96 & 284.95 & 308.29 & 331.93 & 355.81 & 379.90 & 404.16 & 428.56 & 453.06 & 477.65 & 502.32 & \\
\hline 3 & 147.98 & 168.89 & 190.51 & 212.80 & 235.59 & 258.72 & 282.22 & 306.00 & 330.02 & 354.23 & 378.59 & 403.07 & 427.66 & 452.31 & 477.03 & 501.81 & \\
\hline 8 & 136.35 & 159.04 & 182.27 & 205.91 & 229.88 & 254.03 & 278.36 & 302.84 & 327.43 & 352.11 & 376.85 & 401.64 & 426.48 & 451.34 & 476.23 & 501.15 & \\
\hline 9 & 135.37 & 158.23 & 181.62 & 205.38 & 229.45 & 253.68 & 278.08 & 302.62 & 327.25 & 351.96 & 376.73 & 401.54 & 426.40 & 451.28 & 476.18 & 501.10 & \\
\hline 10 & 134.55 & 157.57 & 181.09 & 204.95 & 229.10 & 253.40 & 277.86 & 302.44 & 327.10 & 351.84 & 376.63 & 401.47 & 426.33 & 451.22 & 476.14 & 501.07 & \\
\hline 200 & 126.27 & 151.13 & 176.04 & 200.97 & 225.92 & 250.88 & 275.86 & 300.83 & 325.81 & 350.80 & 375.79 & 400.78 & 425.78 & 450.77 & 475.76 & 500.76 & \\
\hline -Inf & 125.75 & 150.75 & 175.75 & 200.75 & 225.75 & 250.75 & 275.75 & 300.75 & 325.75 & 350.75 & 375.75 & 400.75 & 425.75 & 450.75 & 475.75 & 500.75 & \\
\hline
\end{tabular}

${ }^{*}$ The no-arbitrage upper/lower bounds are $\widetilde{S}_{0}$ and $\max \left(\widetilde{S}_{0}-e^{-r t} K, 0\right)$ for call option when threshold $\bar{L}=\infty$. 
Table A2. Call Option Price Bounds on 5 August 2011 using IBT as benchmark model.

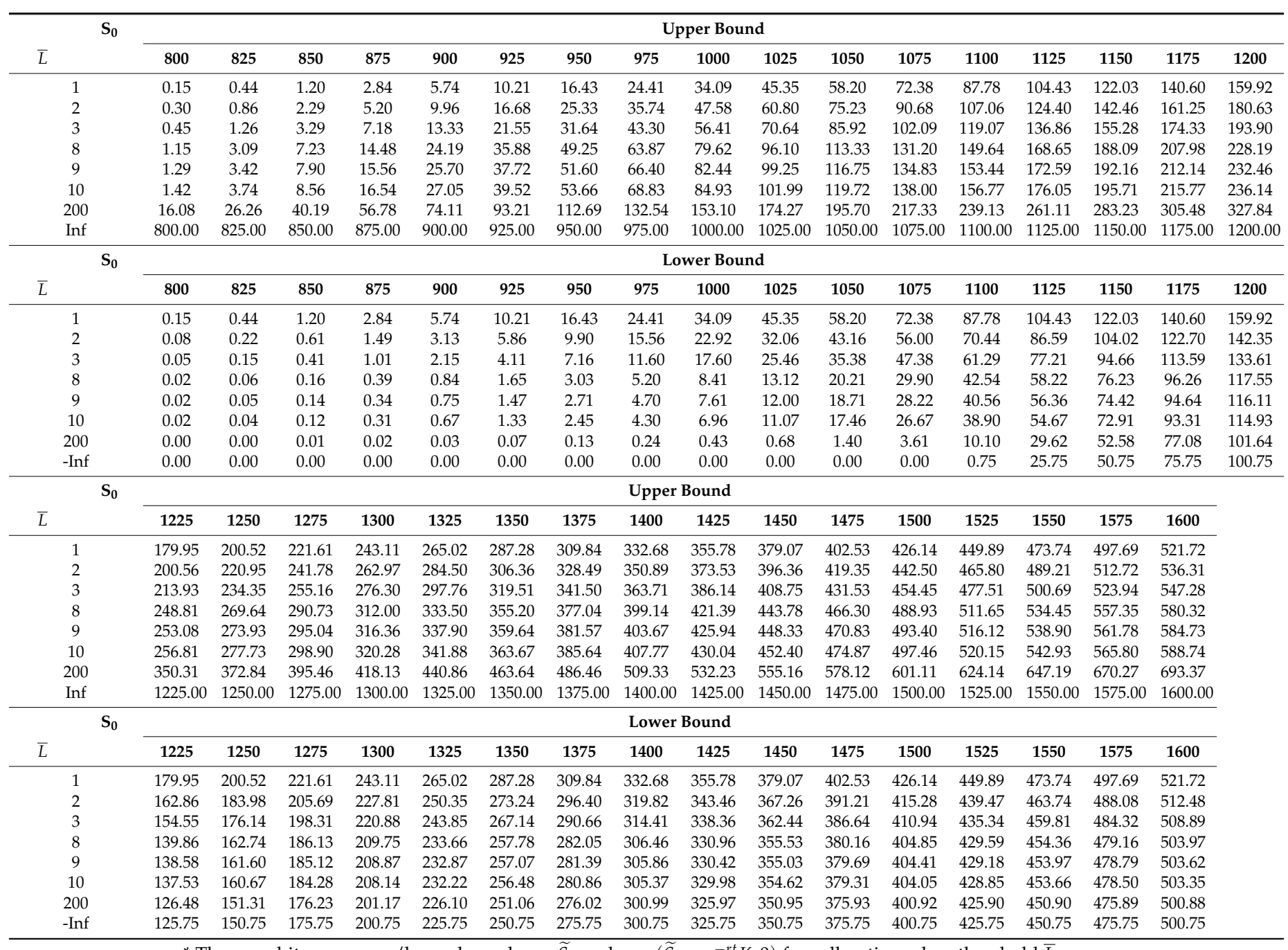

${ }^{*}$ The no-arbitrage upper/lower bounds are $\widetilde{S}_{0}$ and $\max \left(\widetilde{S}_{0}-e^{-r t} K, 0\right)$ for call option when threshold $\bar{L}=\infty$. 


\section{References}

1. Rubinstein, M. The valuation of uncertain income streams and the pricing of options. Bell J. Econ. 1976, 7, 407-425. [CrossRef]

2. Brennan, M.J. The pricing of contingent claims in discrete time models. J. Financ. 1979, 34, 53-68. [CrossRef]

3. Ross, S. Mutual fund separation in financial theory: The separation distributions. J. Econ. Theory 1978, 17, 254-286. [CrossRef]

4. Cochrane, J. Asset Pricing: Revised Edition; Princeton University Press: Princeton, NJ, USA, 2005; ISBN 9780691121376.

5. Lehar, A.; Scheicher, M.; Schittenkopf, C. GARCH vs. stochastic volatility: Option pricing and risk management. J. Bank Financ. 2002, 26, 323-345. [CrossRef]

6. Cochrane, J.; Saa-Requejo, J. Beyond arbitrage: Good-deal asset price bounds in incomplete markets. J. Polit. Econ. 2000, 108, 79-119. [CrossRef]

7. Bernardo, A.; Ledoit, O. Gain, loss and asset pricing. J. Polit. Econ. 2000, 108, 173-206. [CrossRef]

8. Corrado, C.; Su, T. Implied volatility skews and stock index skewness and kurtosis implied by S\&P 500 index option prices. J. Deriv. 1997, 4, 8-19.

9. Jackwerth, J.C.; Rubinstein, M. Recovering probability distributions from contemporary security prices. J. Financ. 1996, 51, 1611-1631. [CrossRef]

10. Breeden, D.; Litzenberger, R. Prices of state-contingent claims implicit in options prices. J. Bus. 1978, 51, 621-651. [CrossRef]

11. Rubinstein, M. Implied binomial trees. J. Financ. 1994, 49, 771-818. [CrossRef]

12. Aït-Sahalia, Y.; Lo, A. Nonparametric estimation of state-price densities implicit in financial asset prices. J. Financ. 1998, 53, 499-548. [CrossRef]

13. Aït-Sahalia, Y.; Lo, A. Nonparametric risk management and implied risk aversion. J. Econom. 2000, 94, 9-51. [CrossRef]

14. Jackwerth, J.C. Recovering risk aversion from option prices and realized returns. Rev. Financ. Stud. 2000, 13, 433-451. [CrossRef]

15. Longstaff, F. Option pricing and the martingale restriction. Rev. Financ. Stud. 1995, 8, 1091-1124. [CrossRef]

16. Aparicio, S.; Hodges, S. Implied risk-neutral distribution: A comparison of estimation methods. In FORC Preprint; Working Paper; Warwick University: Coventry, UK, 1998.

17. Corrado, C. Option pricing based on the generalized lambda distribution. J. Futures Mark. 2001, 21, $213-236$. [CrossRef]

18. De Jong, C.; Huisman, R. From Skews to a Skewed-t: Modelling Option-Implied Returns by a Skewed Student-t. In Proceedings of the IEEE/IAFE/INFORMS 2000 Conference on Computational Intelligence for Financial Engineering, New York, NY, USA, 28 March 2000.

19. Ritchey, R. Call option valuation for discrete normal mixtures. J. Financ. Res. 1990, 13, 285-295. [CrossRef]

20. Melick, W.; Thomas, C. Recovering an asset's implied PDF from option prices: An application to crude oil during the Gulf crisis. J. Financ. Quant. Anal. 1997, 32, 91-115. [CrossRef]

21. Buchen, P.; Kelly, M. The maximum entropy distribution of an asset inferred from option prices. J. Financ. Quant. Anal. 1996, 31, 143-159. [CrossRef]

22. Rockinger, M.; Jondeau, E. Entropy densities with an application to autoregressive conditional skewness and kurtosis. J. Econom. 2002, 106, 119-142. [CrossRef]

23. Härdle, W.; Yatchew, A. Dynamic nonparametric state price density estimation using constrained least squares and the bootstrap. In Working Paper; Humboldt University Berlin: Berlin, Germany, 2002.

24. Mayhew, S. On estimating the risk-neutral probability distribution implied by option prices. In Working Paper; Purdue University: West Lafayette, IN, USA, 1995.

25. Andersen, A.; Wagener, T. Extracting risk neutral probability densities by fitting implied volatility smiles: Some methodological points and an application to the 3M EURIBOR futures option prices. In Working Paper; European Central Bank: Frankfurt, Germany, 2002.

26. Rosenberg, J. Nonparametric pricing of multivariate contingent claims. J. Deriv. 2003, 10, 9-26. [CrossRef]

27. Wang, Y.; Zhao, M.; Han, Y.; Zhou, J. A fuzzy expression way for air quality index with more comprehensive information. Sustainability 2017, 9. [CrossRef] 
28. Wan, H. Pricing American-style basket options by implied binomial tree. In Working Paper; Haas School of Business: Berkeley, CA, USA, 2002.

29. Cox, J.; Ross, S.; Rubinstein, M. Option pricing: A simplified approach. J. Financ. Econ. 1979, 7, $229-263$. [CrossRef]

30. Longarela, I. Gain, loss, and asset pricing: It is much easier. A note. In Working Paper; Stockholm School of Economics: Stockholm, Sweden, 2008.

31. Stephan, J.; Whaley, R. Intraday price change and trading volume relations in the stock and stock option markets. J. Financ. 1990, 45, 191-220. [CrossRef]

32. Bergsma, K.; Fodor, A.; Singal, V.; Tayal, J. Intraday option to stock volume ratios and stock return predictability. Social Science Electronic Publishing. Available online: https://papers.ssrn.com/sol3/papers. cfm?abstract_id=3095239 (accessed on 16 May 2018).

33. Birru, J.; Figlewski, S. Anatomy of meltdown: The risk neutral density for the S\&P 500 in the fall of 2008. J. Financ. Mark. 2012, 15, 151-180. [CrossRef]

34. Stoll, H.; Whaley, R. Programme trading and expiration-day effects. Financ. Anal. J. 1987, 43, 16-28. [CrossRef]

35. Longarela, I. A Simple linear programming approach to gain, loss and asset pricing. Top. Theor. Econ. 2015, 2, 1064. [CrossRef]

36. Pinar, M. Gain-loss pricing under ambiguity of measure. ESAIM Control Optim. Calc. Var. 2010, 16, 132-147. [CrossRef]

37. Voelzke, J.; Mentemeier, S. Computing the substantial-gain-loss-ratio. In CQE Working Papers; Center for Quantitative Economics: Münster, Germany, 2017.

38. Mugwagwa, T.; Ramiah, V.; Moosa, I. The profitability of option-based contrarian strategies: An empirical analysis. Int. Rev. Financ. 2015, 15, 1-26. [CrossRef]

(c) 2018 by the authors. Licensee MDPI, Basel, Switzerland. This article is an open access article distributed under the terms and conditions of the Creative Commons Attribution (CC BY) license (http:/ / creativecommons.org/licenses/by/4.0/). 